\title{
Effects of relative humidity on electrification and lightning discharges in thunderstorms
}

\author{
Zheng Shi ${ }^{1, *}$, Yongbo Tan ${ }^{1}$, Yinping Liu ${ }^{1}$, Jun Liu ${ }^{1}$, Xiaotong $\operatorname{Lin}^{1}$, Mengyi Wang ${ }^{1}$, and Jian Luan ${ }^{2}$ \\ ${ }^{1}$ Key Laboratory of Meteorological Disaster, Ministry of Education (KLME)/Joint International Research Laboratory of Climate \\ and Environment Change (ILCEC)/Collaborative Innovation Center on Forecast and Evaluation of Meteorological Disasters \\ (CIC-FEMD)/Key Laboratory for Aerosol-Cloud-Precipitation of China Meteorological Administration, Nanjing University of \\ Information Science \& Technology, Nanjing, China \\ ${ }^{2}$ Liaoning Branch, China Meteorological Administration Training Center, Shenyang, China
}

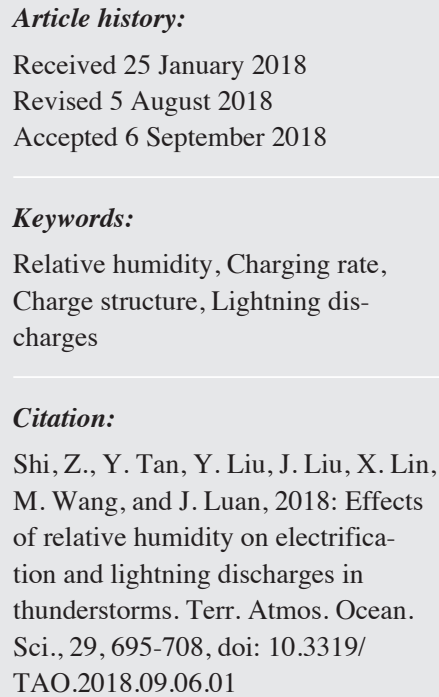

\begin{abstract}
Ten-year measurements of lightning and relative humidity from 2002 - 2011 have been analyzed in the Nanjing city, China. Statistical analysis shows the lightning density is positively correlated to relative humidity during this period. To further investigate the effect of relative humidity on electrification and lightning discharges in thunderstorms, a two-dimensional cumulus model incorporating dynamics, microphysics, and thunderstorm electrification mechanisms is used to present a sensitive study. The results show that the higher relative humidity in surface leads to more cloud droplet and stronger updraft, because of enhanced latent heat releasing from increasing condensation. Greater updraft and cloud water content primarily contribute to stronger ice crystal and graupel particles production with increasing relative humidity. A greater formation of cloud droplet, graupel and ice crystal result in increasing charge separation via non-inductive and inductive mechanism. The total lightning flashes increase as the relative humidity increase from $60-90 \%$, and only tests with high relative humidity of $90 \%$ can produce negative cloud to ground (CG) flashes and positive CG flashes. In addition, the increase of relative humidity condition generally leads to a quicker and stronger convection, which results in earlier electrification and lightning discharges in thunderstorm.
\end{abstract}

\section{INTRODUCTION}

The formation of thunderstorms is closely related to hot and humid air, which can be lifted by updraft in unstable environments. The rising water vapor mainly contribute to the production of various hydrometer particles. Therefore, relative humidity may be a key factor affecting thunderstorm microphysics and dynamics, and the water vapor perhaps plays a crucial role in thunderstorm electrification.

The understanding of the relationships between the relative humidity and electrification of thunderstorms is one of the key questions of theoretical and applied physics of clouds. Williams and Sátori (2004) have presented a mathematical function dependence of mean tropical thunderstorm flash rate on cloud base height based on surface thermodynamic measurements. It must be stated that the relative

\footnotetext{
* Corresponding author

E-mail: gyshiz@126.com
}

humidity is the key surface thermodynamic variable. It has been reported that higher relative humidity results in more lighting activities at dry regions and less lighting activities at wet regions (Xiong et al. 2006). In addition, CG lightning activity in thunderstorms are related to several environmental features which including the humidity condition (Rosenfeld 1999; Petersen and Rutledge 2001; Cifelli et al. 2002). Thereafter, Lawrence et al. (2007) suggested that the polarity of CG lightning in severe storms was controlled by environment parameters which directly affected storms structural, dynamical, and microphysical properties. On the other hand, the humidity condition of air has a profound influence on the "dry lightning" (lightning that occurs without significant rainfall) production, which potentially affects the chance that lightning will cause a fire (Dowdy and Mills 2012).

Lightning produced from thunderstorms is consistent with the charge characteristic. For example, Tan et al. (2014a) revealed that the lightning types are related to the 
space charge and electric potential. A lower positive charge region in thunderstorms is capable of producing negative CG lightning (Tan et al. 2014b). Additionally, the inverted intracloud (IC) lightning is observed from the thunderstorms which exhibits a large lower positive charge centers (Qie et al. 2005). Therefore, the space charge structure is an important factor for lightning formation. At present there are two primary categories of charge separation mechanisms that have been proposed to explain thunderstorm electrification: the non-inductive charging separation and inductive charging separation. Non-inductive charge separation via rebounding graupel-ice collisions can be considered as a primary mechanism in thunderclouds (Takahashi 1978; Jayaratne et al. 1983; Gardiner et al. 1985; Saunders et al. 1991; Brooks et al. 1997; Saunders and Peck 1998; Guo et al. 2016), meanwhile inductive charging is produced between colliding and rebounding cloud particles which are polarized by a vertical electric field. Therefore, we can conclude that electrification and lightning discharge is significantly based on microphysics development in thunderstorms.

The response of cloud microphysics to different relative humidity condition behave distinctly. For example, during cloud formation, the aerosol particles can be activated to be cloud droplet. Such a process is strongly related to water vapor in cloud (Köhler 1936). Water may directly deposit onto ice nuclei (IN) as ice crystals, and then they grow mainly vapor deposition. Such the processes are very sensitive to the supersaturation or cloud water content (Pruppacher and Klett 1997). Over the past years, much have been learned regarding the interaction between aerosol and cloud. Numerous studies using parameterized models and remote sensing observation have investigated greater concentrations of aerosols result in the production of more small cloud droplets and reduced collision efficiencies, which can delay the formation of raindrops (e.g., Nakajima et al. 2001; Feingold et al. 2003; Khain et al. 2005, 2008; Rosenfeld et al. 2008; Fan et al. 2017). In addition, several mechanisms have been proposed to elaborate the role of aerosols on cloud dynamic, microphysics development and precipitation under different meteorological scenarios. It has been suggested that the role that cloud base humidity plays in the response of precipitation to increased cloud condensation nuclei $(\mathrm{CCN})$ (Fan et al. 2007; Saleeby et al. 2013; Carrió and Cotton 2014; Zhao et al. 2016). When the humidity in cloud is very low, Ackerman et al. (2004) demonstrated that more and smaller cloud drops (high aerosol concentration condition) may enhance evaporation in the downdraft region of cloud edges, which leads to lower cloud fraction, cloud size and cloud depth. Similarly, previous studies suggested that in the condition of strong water vapor content, the larger concentration of $\mathrm{CCN}$ leads to more supercooled water production, leaving more cloud water for ice particles to collect, and thus the solid state precipitation increase rapidly. However, the effect of $\mathrm{CCN}$ on precipitation is insignificant when the rela- tive humidity is low (Fan et al. 2007; Zhao et al. 2016).

The discussions above suggest that relative humidity have a significantly influence on cloud microphysics, and due to the mechanisms of thunderstorm electrification and lightning discharges are intrinsically linked to microphysics and hydrometeor particles, the possible effects of relative humidity on thunderstorm electrification and lightning discharges should be studied. In this work, we perform a date analysis to elucidate the relationship between relative humidity and lightning activity. In addition, a two-dimensional cumulus model with detail cloud microphysics is used, and we present sensitivity studies of humidity condition on thunderstorm electrification and lightning frequency.

\section{DATA SOURCES AND MODEL DESCRIPTION}

\subsection{Data Description}

Nanjing is located in the north of subtropical zone, which is a sub-tropical humid monsoon climate zone with clear seasons and abundant rainfall. The lightning activity shows peak in summertime (Tan et al. 2016). In order to investigate the correlation between lightning activity and relative humidity at the surface in Nanjing, the lightning data (lightning flash density) are taken from Optical Transient Detector (OTD) on the MicroLab-1 satellite (later renamed OV-1) and Lightning Imaging Sensor (LIS) aboard the Tropical Rainfall Measuring Mission (TRMM) satellite. The lightning data is low resolution monthly time series with a spatial resolution of $2.5 \times 2.5$ degree. The detection efficiency of LIS is more than $80 \%$ in both day-time and night-time, and the obtained lightning flashes include both intracloud and cloud-to-ground lightning. The surface humidity data are taken from National Centers for Environmental Prediction (NCEP) and National Center for Atmospheric Research (NCAR) reanalysis data products. To unify with the grid of surface humidity data, the lightning data have been converted to $1^{\circ} \times 1^{\circ}$ by the method of Inverse Distance Weighted. Thereafter, Nanjing has four points $\left(31.5^{\circ} \mathrm{N}, 118.5^{\circ} \mathrm{E} ; 31.5^{\circ} \mathrm{N}, 119.5^{\circ} \mathrm{E} ; 32.5^{\circ} \mathrm{N}, 118.5^{\circ} \mathrm{E}\right.$; $32.5^{\circ} \mathrm{N}, 119.5^{\circ} \mathrm{E}$ ), and the data of these points are averaged to get final representative value. The data are integrated for three months i.e., June, July, and August from 2002 - 2011. The monthly mean relative humidity at the surface in summertime is used in this paper reflects the actual meteorological conditions during lightning storms in Nanjing.

\subsection{Model Description}

The numerical model used in this study was developed by $\mathrm{Hu}$ and $\mathrm{He}$ (1987). It is a non-hydrostatic cumulus model. As described in Shi et al. (2015), the microphysics scheme has five hydrometeor categories with a gamma function distribution. The five categories are cloud droplets, rain, ice crystal, graupel, and hail. The model predicts mixing ratio 
and number concentration of each category. As discusses in Appendix A, cloud droplets are formed through activation of CCN. Raindrops can be produced from autoconversion of cloud droplets or melting of ice particles. The microphysical conversions include condensation and evaporation of five types of particles. Nucleation of ice crystals occur both through homogeneous-freezing of cloud droplets and by heterogeneous nucleation caused by IN (ice nuclei) (for details see Appendix B). The secondary ice multiplication depends on the number of cloud droplets with diameter greater $24 \mu \mathrm{m}$, which is based on Mossop (1976). Since large amount of supercooled water reside in cumulus could, ice crystal with the diameter over the critical value $(0.03 \mathrm{~cm})$ will grow up quickly during colliding with supercooled water, and the growth speed is larger than that in the process of sublimation. Under this condition, as soon as the diameter of ice crystal exceeds $0.03 \mathrm{~cm}$, ice crystal should become to graupel. Similarly, after a significant growth of graupel (the diameter exceeds $0.5 \mathrm{~cm}$ ), the graupel should be assigned to hail. In addition, the microphysical processes include various collisions between two types of particle (collision between cloud droplet and ice crystal, rain, graupel, and hail; collision between rain and ice crystal; collision between rain and graupel, and hail; collision between ice crystal and graupel, and hail). It should be noted that the size of ice crystals plays an important role in collision processes between ice crystals and cloud droplets, and the processes in the model are allowed to arise only when the size of ice crystals is above $0.03 \mathrm{~cm}$. The collision between ice crystals and graupel highly generally depends on relative velocity of the collisions, hydrometeors concentration and the size spectrum.

The electric charges are carried by each type of hydrometeor. Inductive and noninductive mechanisms are both considered. The electrification parameterization includes the inductive charge separation between graupel and cloud droplet under the external electric field and non-inductive mechanisms between graupel and ice crystal under the consisting of ice particles and supercooled water. Inductive collision charging parameterization is based on Ziegler et al. (1991). The GZ (Gardiner/Ziegler) noninductive charge separation parameterization (Gardiner et al. 1985; Ziegler et al. 1991; Mansell et al. 2005) is used in all the simulations.

Lightning discharges are parameterized based on Tan et al. (2006). Lightning initiation uses the runaway electron threshold for break-even field and thereafter bidirectional channels are propagated in a stochastic step-by-step fashion. The leaders of IC (intracloud) lightning do not reach ground, and a height threshold $(1.5 \mathrm{~km}$ or 6 grid points above ground) is used to define a flash to be a CG (cloud to ground) lightning (includes $+\mathrm{CG}$ and $-\mathrm{CG}$ ).

Under these conditions, a resolution of $250 \mathrm{~m}$ and time steps of 2 seconds are used to calculate the microphysical and electrification processes in the $76 \mathrm{~km} \times 20 \mathrm{~km}$ domain. Thereafter, a conversion scheme from coarse to fine resolution charge distribution is used when simulating fine resolution $(25 \mathrm{~m})$ discharge processes.

A mountain storm of SEET (Studies of Electrical Evolution in Thunderstorms) is simulated. The initial sounding conditions for the tests are given by a profile of temperature, dew point and wind shear as shown in Fig. 1. The SEET case was conducted in July and August of 1999 at the langmuir laboratory for atmosphere research in the mountain of central New Mexico (Coleman et al. 2003), and the atmospheric sounding profiles (Fig. 1) on 31 July 1999 are taken form NCEP (National Centers for Environmental Prediction) grids data near to the observing site. The environmental

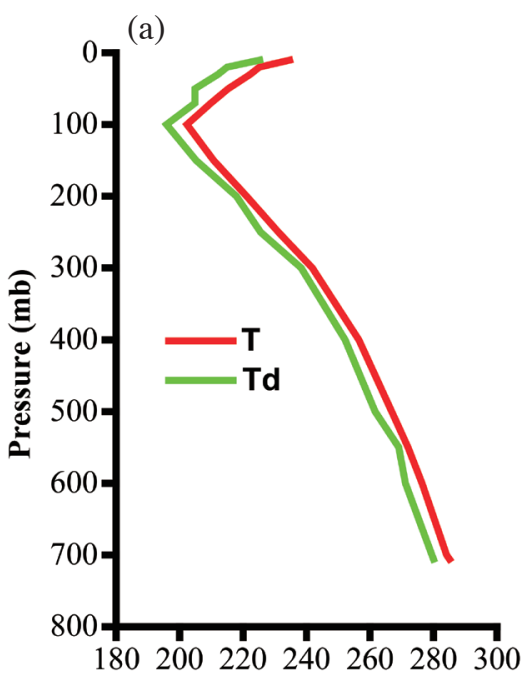

T\&Dew Point (K)

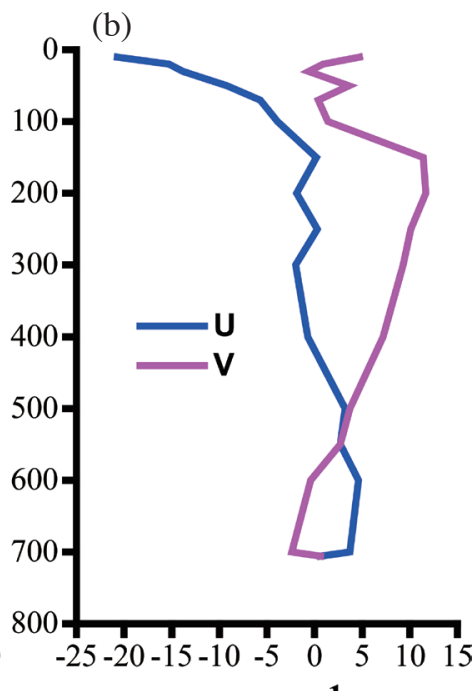

$\mathrm{U} \& \mathrm{~V}\left(\mathrm{~m} \mathrm{~s}^{\mathbf{- 1}}\right)$

Fig. 1. The initial sounding date for SEET case (Coleman et al. 2003) used in the simulation. (a) Temperature (T) and dew point (Td), (b) horizontal winds $\mathrm{U}$ and $\mathrm{V}$. 
sounding which has been used in related studies (Tan et al. 2006, 2014b; Tao et al. 2009; Shi et al. 2016) is suitable for this sensitive modeling study. Thereafter, the effect of relative humidity (RH) on thunderstorm development is evaluated for four cases. It must be noted that the different RH conditions are set by changing the environment humidity stratification of the SEET case at initial time, and the RH at the surface is $60,70,80$, and $90 \%$, respectively. The RH of 60 and $90 \%$ represent relative dry and relative humidity condition.

\section{RESULTS AND DISCUSSIONS}

\subsection{Analysis of Observation of Lightning Flashes and Humidity}

Measurements of lightning flashes and relative humidity from 2002 - 2011 are analyzed to investigate the relationship between lightning and humidity over Nanjing city. Figure 2 depicts the variation of the mean of the lightning density over different relative humidity levels. The mean flash density roughly starts increasing from $75-95 \%$. It must be pointed out that although all mean monthly relative humidity are larger than $75 \%$, lightning flashes also can be produced in some regions where the surface $\mathrm{RH}$ is less than $75 \%$. The mean lightning density between 74 and $78 \%$ is $0.56 \mathrm{fl} \mathrm{km}^{-2} \mathrm{~d}^{-1}$, which is larger than that in the range of $78-86 \%$. This perhaps can be attributed to the few sample. It also can be found from Fig. 2 that a large lightning activity may be correlated with the relative humidity that above $90 \%$, which implies the high relative humidity is suitable for thunderstorm development and lightning production. Application of statistical significance shows that lightning density and relative humidity are statistically significant to the level of the $p<0.001$, and the correlation coefficient $R$ is 0.43 (Fig. 2). Therefore, one can conclude that lightning show positive correlation with relative humidity. Additionally, lightning activity can be affected by a host of factors. The urban heat island influence can be one of the main cause response for enhanced lightning activity (Steiger et al. 2002; Naccarato et al. 2003; Kar et al. 2009). It also has been reported that the increase in aerosol concentration can increase lightning activity in thunderstorm (Yuan et al. 2011; Mansell and Ziegler 2013; Tan et al. 2017). In order to remove these confuse factors, a model study should be conducted to investigate the effect of relative humidity on electrification and lightning activities.

\subsection{Dynamic and Microphysics}

To investigate the RH condition effect on thundercloud properties, four cases are calculated for thunderstorms. The thunderstorm is significantly affected by relative humidity. Figure 3 shows the temporal evolution of maximum and minimum vertical velocities in four cases. From the evolution of the modeled maximum and minimum vertical ve- locities within the domain, the variations in the updraft and downdraft are roughly similar and both velocities reach the peak at about $32 \mathrm{~min}$. In addition, the vigorous development of thunderstorm is mainly in the time range from $10-50 \mathrm{~min}$. The profiles of maximum updraft velocity are roughly similar in four cases. In the developing stage from $5 \mathrm{~min}$ to about $32 \mathrm{~min}$, the quickly increase in updraft velocity is mainly result from condensation and the release of latent heat. Meantime, the maximum updraft velocity increases greatly when the RH increases from $60-90 \%$ (see Table 1), primarily because the more water vapor in the high RH case is related to more latent heat released by the process of hydrometer particles condensation. Similarly, the downdraft increases with RH increasing, which can be explained because of a larger mass loading of hydrometeors to decrease buoyancy in high RH case. In addition, strong updraft $\left(>10 \mathrm{~m} \mathrm{~s}^{-1}\right)$, which denotes a profound factor in lightning generation, is characteristic of thunderstorms in developing and mature stage (Williams et al. 1991). It can be found from Fig. 3 that the thunderstorm with updraft velocities greater than $10 \mathrm{~m} \mathrm{~s}^{-1}$ is significantly more prominent in high $\mathrm{RH}$ case than that in low RH case. Therefore, the vertical velocities in four cases exhibit noticeable differences, indicating that an alteration of the structure and development of the thunderstorm by relative humidity.

As shown in Fig. 4, when RH increase from 60 - 90\%, the cloud droplet mixing ratio is sensitive to $\mathrm{RH}$, and the maximum cloud droplet concentration in four cases is 3.11 $\times 10^{7}, 4.14 \times 10^{7}, 4.9 \times 10^{7}$, and $5.5 \times 10^{7} \mathrm{~kg}^{-1}$ respectively. Since the surface relative humidity in four cases is set to be largely difference, the content of water vapor in thundercloud is profoundly sensitive to the RH. As illustrated in Fig. 5, higher RH produced a larger water vapor mixing ratio. The supersaturation is diagnosed at each time step from the predicted water vapor and temperature, and thus the supersaturation (with respect to liquid water) increases with more water vapor supplied in thunderclouds. Due to the activation of aerosol particles is closely related with the absorption of water vapors, the great supersaturation in high RH case leads to the enhancement of the cloud droplet production. After about $20 \mathrm{~min}$, the cloud droplet is consumed by the autoconversion and collisions process, and thus the content of cloud droplet decrease dramatically (Fig. 4). The cloud droplet mean size in four cases is about 19.05, 21.56, 23.21, and $35.45 \mu \mathrm{m}$, respectively (see Table 1). The largest size of cloud droplet arises in the high RH case because a great amount of water vapors are supplied for condensation, and thus cloud droplets are efficiently converted to raindrops. Since the auto-conversion of cloud droplet-rain is mainly responsible for the rain production in the development stage, it is not hard to understand that the greater rain production is consistent with increasing $\mathrm{RH}$ (see Fig. 4). Figure $4 \mathrm{~h}$ also shows more raindrops residing at about $60 \mathrm{~min}$ in the high RH case compared to the other cases. This occurs because 


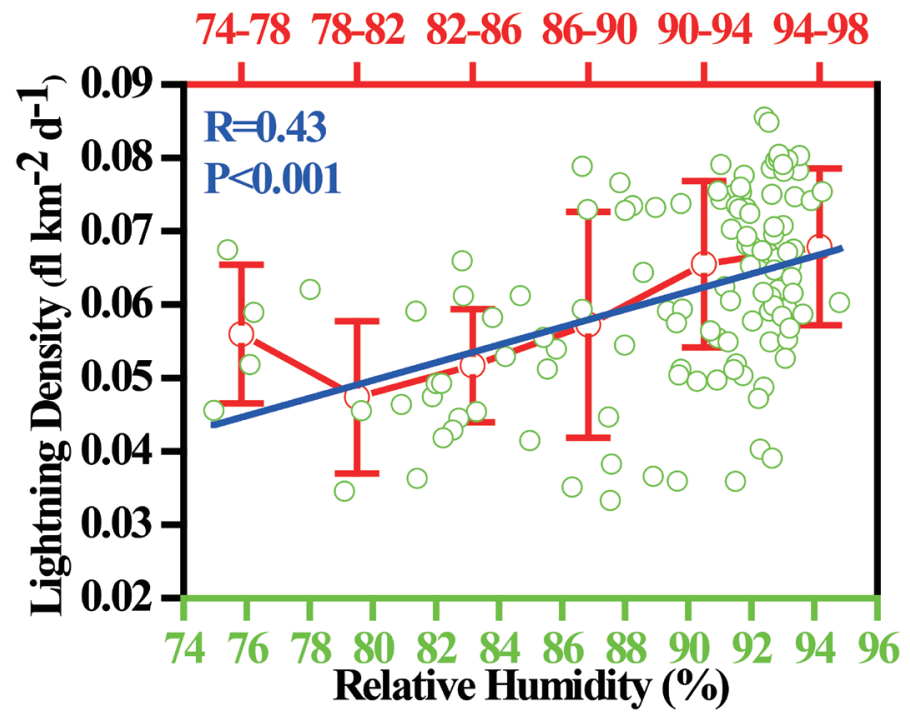

Fig. 2. Lightning density for different relative humidity condition. Scattered diagram of lightning density and relative humidity over Nanjing city with line of best fit.

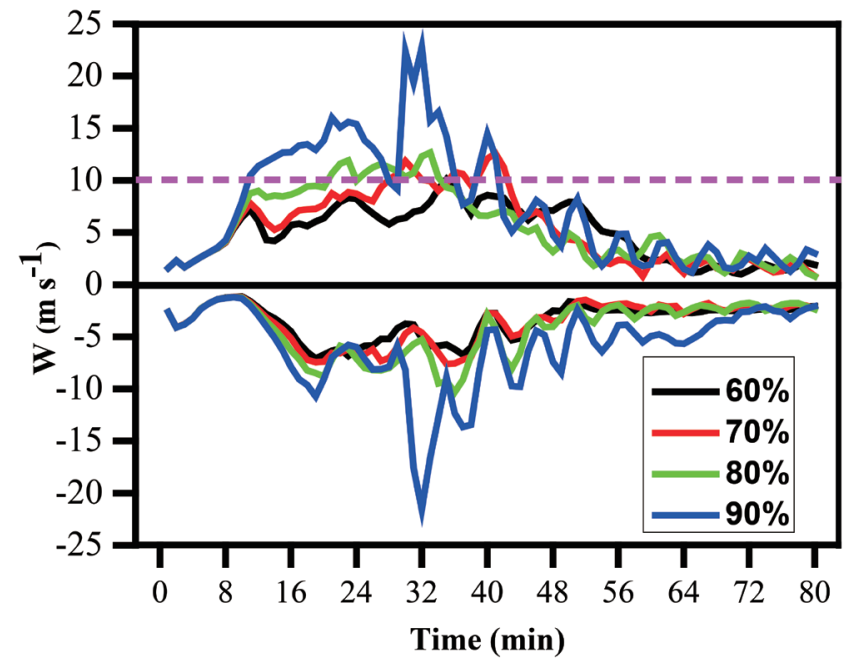

Fig. 3. Time evolution of maximum and minimum vertical velocities in four cases.

Table 1. Comparisons of the results from four case.

\begin{tabular}{ccccc}
\hline Case & $\mathbf{R H}=\mathbf{6 0 \%}$ & $\mathbf{R H}=\mathbf{7 0 \%}$ & $\mathbf{R H}=\mathbf{8 0 \%}$ & $\mathbf{R H}=\mathbf{9 0 \%}$ \\
\hline Max. updraft $\left(\mathrm{m} \mathrm{s}^{-1}\right)$ & 10.13 & 12.57 & 12.66 & 22.36 \\
Mean. cloud droplet diameter $(\mu \mathrm{m})$ & 19.05 & 21.56 & 23.21 & 35.45 \\
Mean. rain diameter $(\mu \mathrm{m})$ & 313.65 & 365.78 & 412.56 & 567.34 \\
Mean. ice crystal diameter $(\mu \mathrm{m})$ & 186.23 & 263.67 & 285.89 & 286.54 \\
Mean. graupel diameter $(\mathrm{mm})$ & 1.18 & 1.40 & 2.09 & 2.48
\end{tabular}


(a)

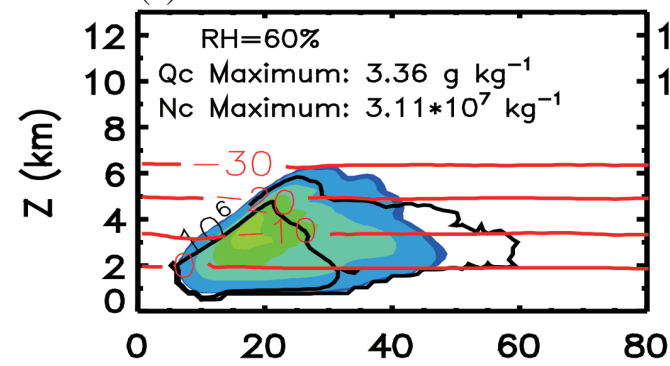

(c)

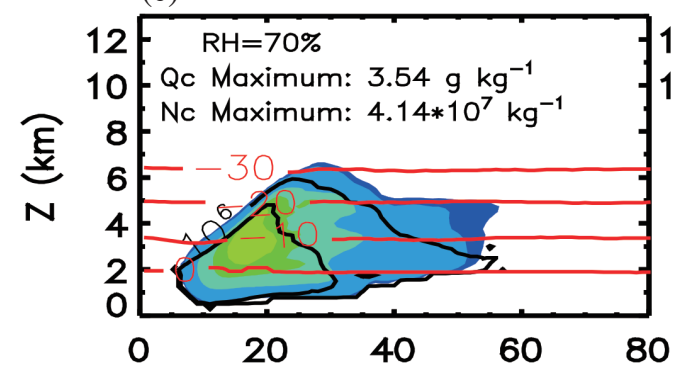

(e)

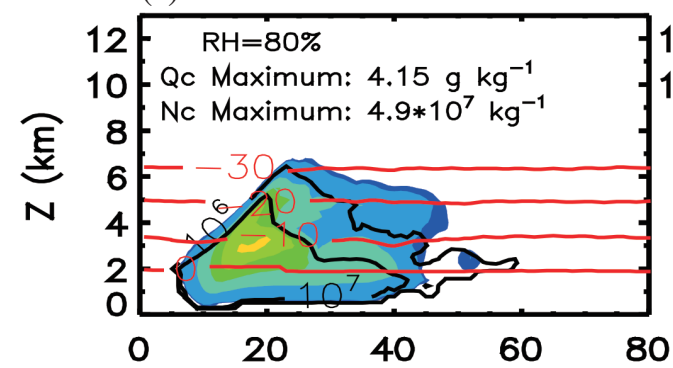

(g)

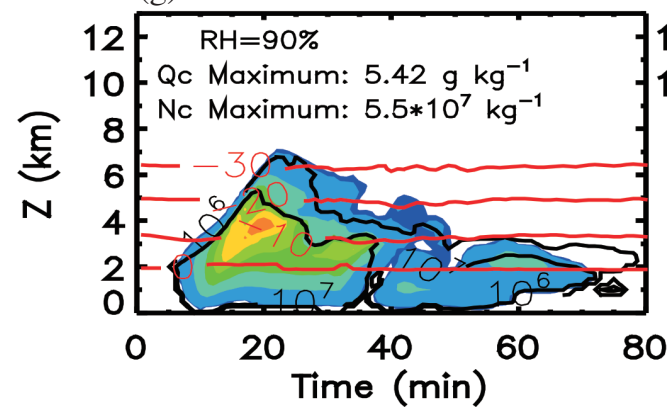

(b)

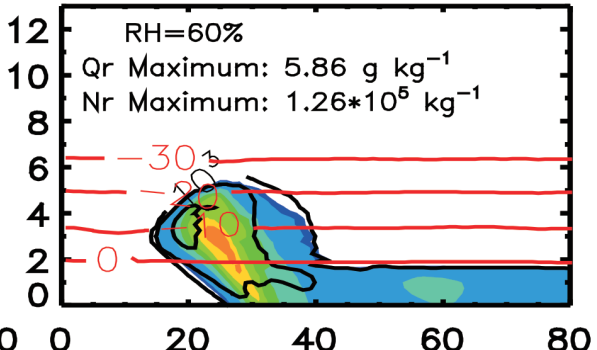

(d)

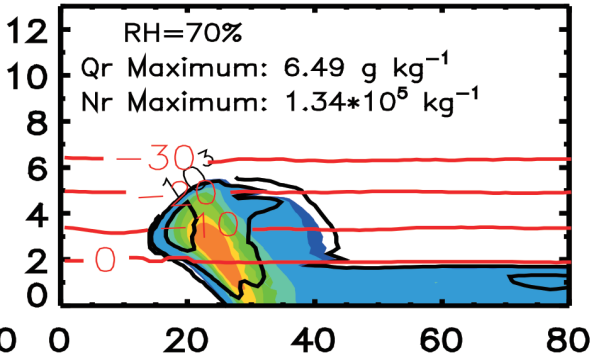

(f)

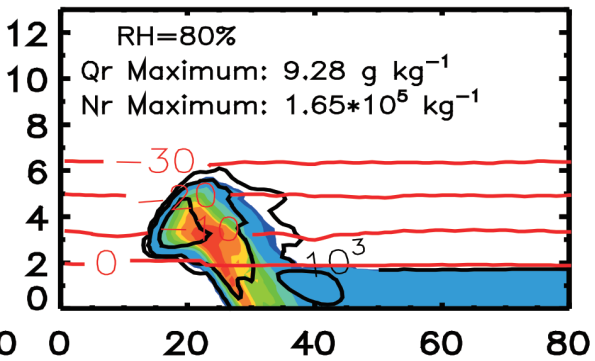

(h)

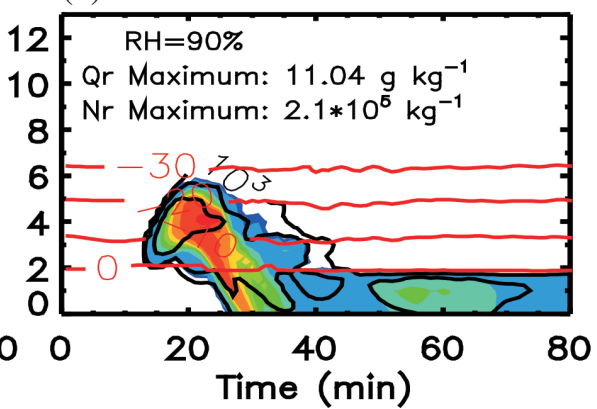

$\mathrm{g} \mathrm{kg}^{-1}$

10.00

7.00

5.00

4.00

3.00

2.00

1.00

0.10

0.05

Fig. 4. Time-height plots showing the mixing ratio (shaded region) and number concentration of cloud droplet [(a), (c), (e), (g)] and rain [(b), (d), (f), (h)] evolution in four cases. Isotherms (thin horizontal red lines at $-30,-20,-10,0^{\circ} \mathrm{C}$ is at same in all panels). Cloud droplet number concentration with contour intervals of $\left.10^{6}, 10^{7}, 10^{8}, 10^{9} \mathrm{~kg}^{-1}\right)$, and rain number concentration with contour intervals of $\left.10^{3}, 10^{4}, 10^{5}, 10^{6} \mathrm{~kg}^{-1}\right)$. The mixing ratio of hydrometer particles is defined as $\mathrm{Q}$, while $\mathrm{N}$ represents the number concentration. 


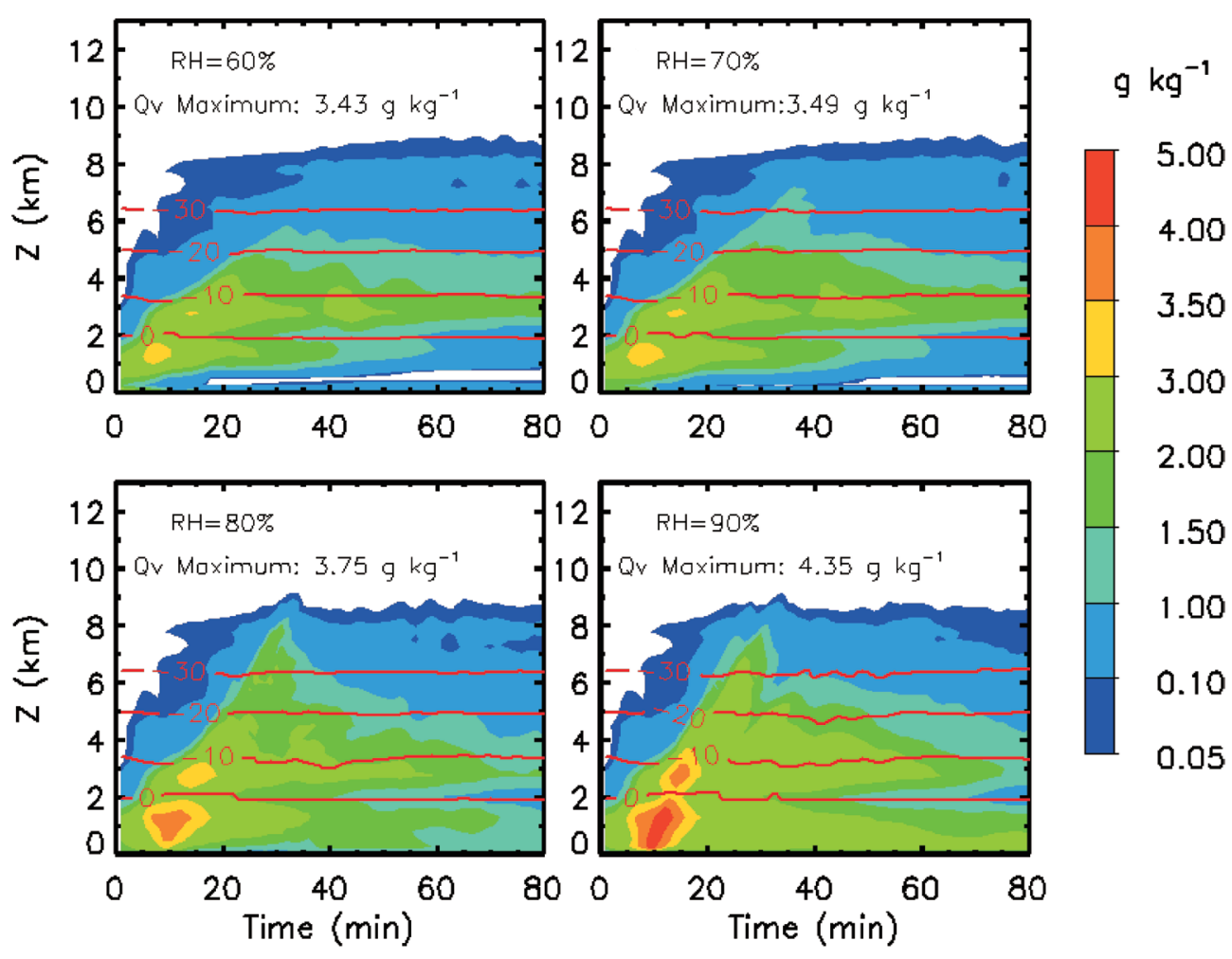

Fig. 5. Time-height plots showing the mixing ratio of water vapor evolution in four cases.

melting of ice particles is enhanced with larger ice particles formation. Similar to the case of cloud droplet, the characteristic size of raindrop increases significantly with the RH increasing (Table 1), perhaps mainly resulted from an enhanced collection of smaller liquid particles.

After about $20 \mathrm{~min}$, ice crystal formation starts and increases very rapidly. Higher RH leads to earlier ice crystal production (Fig. 6). The homogenous droplet freezing and heterogeneous nucleation are the major contributors for ice crystal production, and some ice crystals are produced during graupel riming collection of cloud droplet with diameter greater than $24 \mu \mathrm{m}$ (ice multiplication). Higher RH enhances the condensation of water vapor on the newly formed ice crystals. The high RH case is associated with more cloud water content lifted by stronger updrafts, and thus it is favorable for ice-nucleation, droplet freezing and the collision coalescence between ice crystals and cloud droplet. Therefore, the ice crystal content increases significantly (Fig. 6). The mean size of ice crystals also is sensitive to the changes in RH (Table 1). Graupel is firstly produced by ice-graupel auto-conversion, and both the collisions between liquid drop and ice particles play a significant role in the development of graupel growth. The enhanced graupel content with increasing $\mathrm{RH}$ is primarily due to enhanced cloud water content and stronger ice crystal production (Fig. 6). In addition, an increase in the graupel mixing ratio residing in the vertical range from 0 to $-20^{\circ} \mathrm{C}$ with higher $\mathrm{RH}$ is mainly arrtributed to two collision processes (collision between raindrop and ice crystal and collision between graupel and raindrop). A slight enhancement with increasing $\mathrm{RH}$ is seen from the mean of character size of graupel. Note that the enlarged size of ice particles (ice crystals and graupel) in the higher RH case is primary associated with the enhancement of cloud water collection in thunderclouds. In addition, the earlier ice particles formation and reach the peak content for the high RH case is attributable to more latent heat release, increasing the updraft, which leads to more efficient mixed phase process (see Fig. 6).

Generally, when RH increases from $60-90 \%$, the thunderclouds show a quicker and stronger development, and the hydrometeor content and updraft velocity are pronounced sensitive to $\mathrm{RH}$.

\subsection{Charging Rate}

To show the temporal evolution of particles acquiring charge in each simulation. Figure 7 shows the time evolution of non-inductive charging rates by ice crystal and inductive charging rates by graupel. It can be seen from Figs. 7a - d that the positive non-inductive charging rates are highest at altitudes of $5-9 \mathrm{~km}$, while the negative non-inductive charge mainly resided at $3-5 \mathrm{~km}$. Therefore, it is clear that ice crystal charged positively at lower temperatures $\left(<-15^{\circ} \mathrm{C}\right)$, and ice crystal gained negative charge in the regions where 
(a)

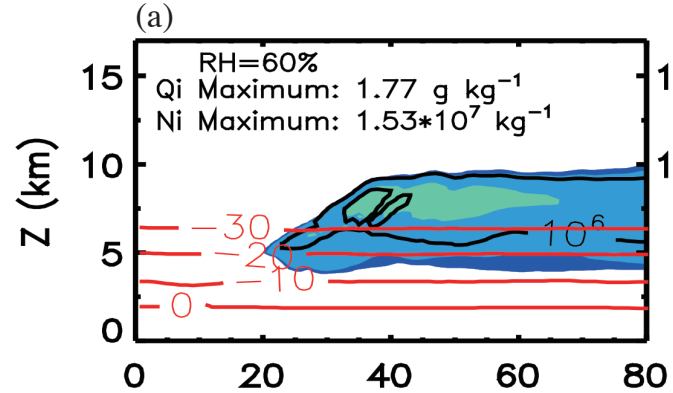

(c)

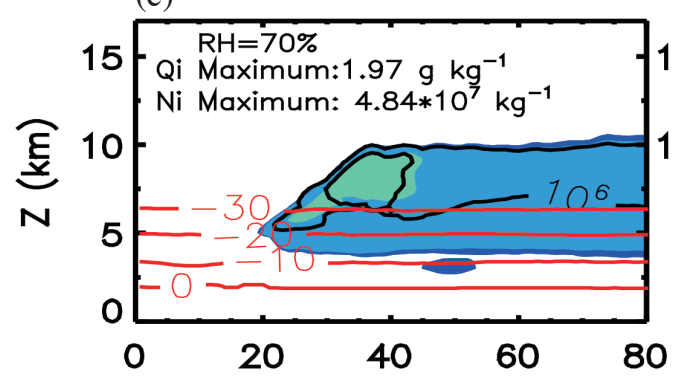

(e)

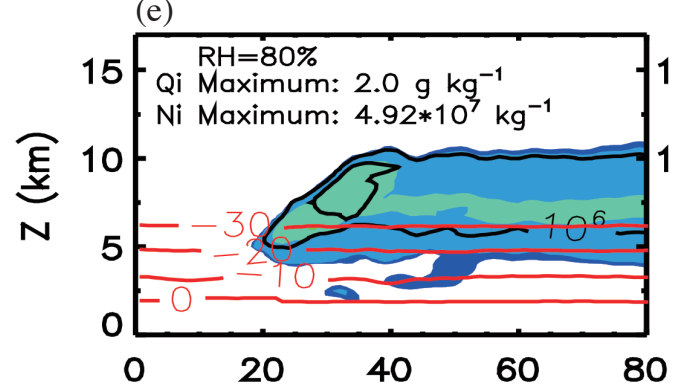

(g)

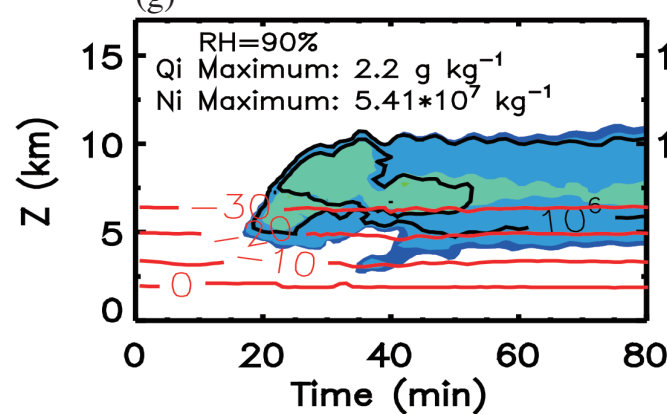

(b)

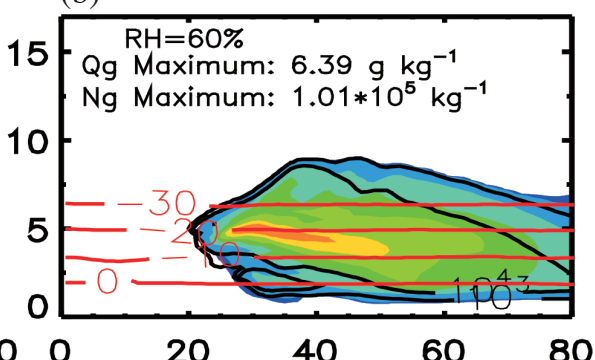

(d)

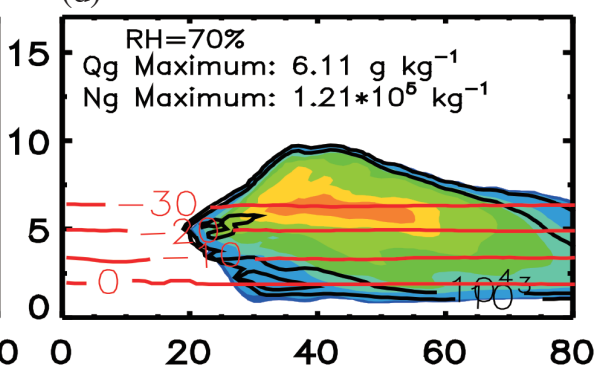

80

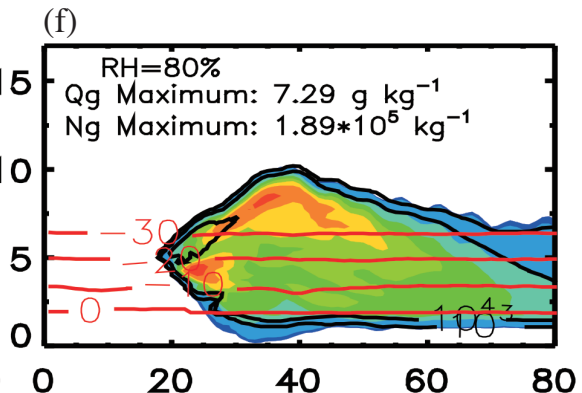

(h)

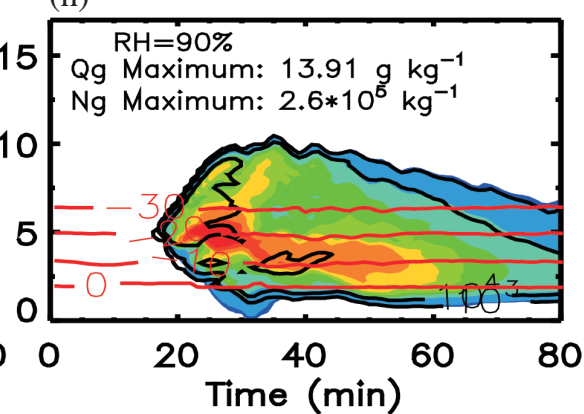

$\mathrm{g} \mathrm{kg}^{-1}$

10.00

7.00

5.00

4.00

3.00

2.00

1.00

0.10

0.05

Fig. 6. Time-height plots showing the mixing ratio (shaded region) and number concentration of ice crystal [(a), (c), (e), (g)] and graupel [(b), (d), (f), (h)] evolution in four cases. Isotherms (thin horizontal red lines at $-30,-20,-10,0^{\circ} \mathrm{C}$ is at same in all panels). Ice crystal number concentration with contour intervals of $10^{6}, 10^{7}, 10^{8}, 10^{9} \mathrm{~kg}^{-1}$, and graupel number concentration with contour intervals of $10^{3}, 10^{4}, 10^{5}, 10^{6} \mathrm{~kg}^{-1}$. 
(a)

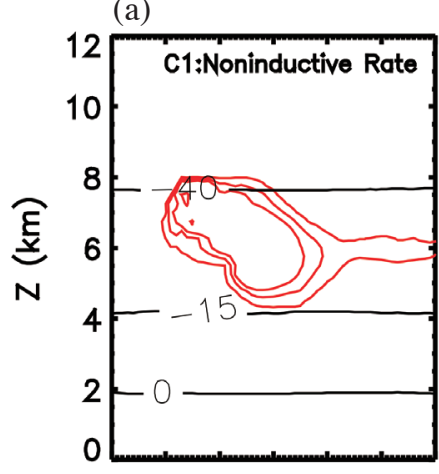

20304050607080

(e)

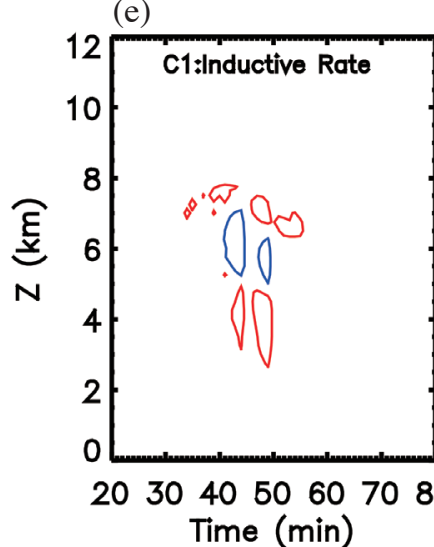

(b)

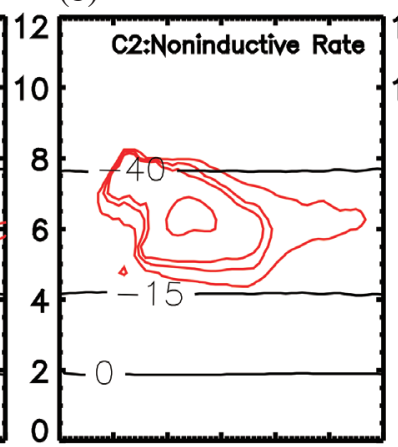

(c)

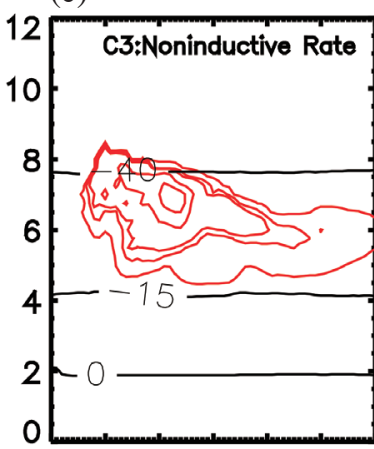

(d)

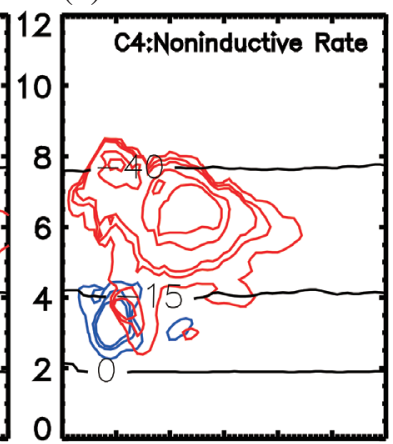

(f)

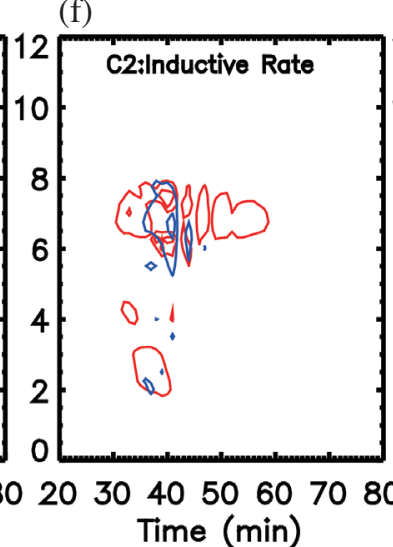

(g)

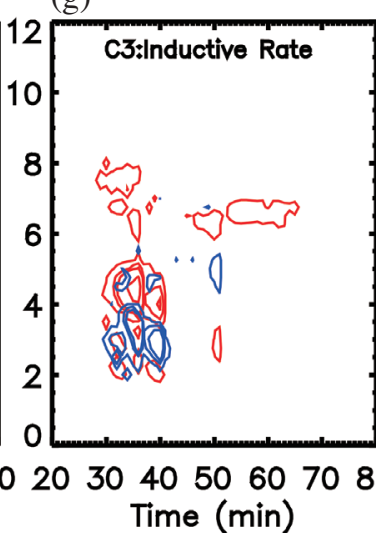

(h)

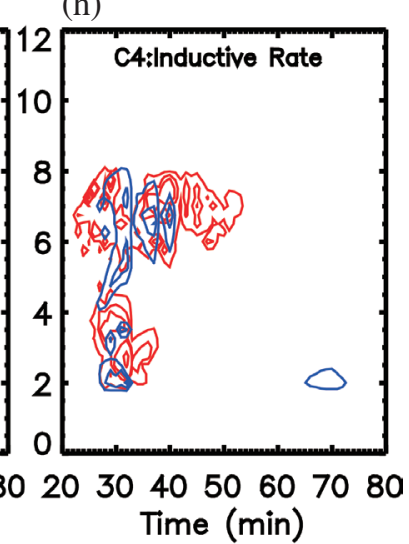

Fig. 7. Time-height plots showing the noninductive (by ice crystal) and inductive (by graupel) charging rate evolution. (a) - (d) Noninductive charging between ice crystal and graupel in four cases. (e) - (h) Inductive charging between graupel and cloud droplets in four cases. Positive (red) and negative (blue) charging rates with contour intervals of $\pm 1, \pm 5, \pm 10, \pm 50, \pm 100, \pm 600 \mathrm{pC} \mathrm{m}^{-3} \mathrm{~s}^{-1}$. Isotherm (horizontal black lines at $0^{\circ} \mathrm{C},-15^{\circ} \mathrm{C}$, and $-40^{\circ} \mathrm{C}$ ) is in the panel.

the temperature is higher $\left(>-15^{\circ} \mathrm{C}\right)$. Table 2 gives the maximum noninductive charging rate in four cases. The increase in positive non-inductive charging rate with $\mathrm{RH}$ increases from $60-90 \%$ is well correlated to the stronger production of ice crystal and graupel in the cloud. Because ice crystals in $90 \% \mathrm{RH}$ reside in the low levels of the storm where the temperature above $-15^{\circ} \mathrm{C}$, ice crystal charges negatively. Since the $90 \% \mathrm{RH}$ case shows an obvious enhancement on graupel mixing ratio in the higher temperature region, the negative noninductive charging rate is larger than that in the other cases (Table 2). Additionally, non-inductive charge separation between ice crystal and graupel mainly contributes to the main upper positive charge region and the middle negative charge region.

A picture of the inductive charging rates in four cases is listed by the time-height plots in Figs. 7e - h. The inductive charging rates roughly reside between $3-9 \mathrm{~km}$, and the inductive charging process play a significant role in enhancing the charge structure. The positive inductive charging of graupel perhaps makes a greater contribution to the lower positive charge region. It can be seen from Table 2 that the positive and negative inductive charging rate demonstrates an increasing trend with RH increasing, which primary aris- es from an increase in the amount of cloud droplet and graupel. In addition, two factors that affect inductive charging process are electric field and hydrometer particles content. An increase in vertical electric field arising from non-inductive charging enhancement can promote the charge separation between grapuel and cloud droplet, and greater production of cloud droplet and graupel below the attitude of $6 \mathrm{~km}$ leads to stronger inductive charge separation in higher $\mathrm{RH}$ cases. Therefore, Cases of $80 \% \mathrm{RH}$ and $90 \% \mathrm{RH}$ produces inductive charging rate below $6 \mathrm{~km}$ is greater than that in cases of $60 \%$ RH and $70 \%$ RH (Fig. 7).

\subsection{Electrification and Lightning Discharges}

Since the storms are reaching its mature stage and the electrical field is strong enough, the lightning flashes are initiated in thunderstorms. The Fig. 8 shows the first lightning discharges and per-discharge charge structure in four cases. The charge structure from the case of $60 \%$ shows a normal polarity dipole with a pile of positive charge over negative charge region. An intracloud (IC) lightning flash composing of a negative leader traveling upward through positive charge and a positive leader traveling downward through negative 
Table 2. The charge separation rate obtained from four cases simulation.

\begin{tabular}{|c|c|c|c|c|}
\hline \multirow{2}{*}{ Case } & \multicolumn{2}{|c|}{ Noninductive Charging Rate $\left(\mathrm{pC} \mathrm{m}^{-3} \mathrm{~s}^{-1}\right)$} & \multicolumn{2}{|c|}{ Inductive Charging Rate $\left(\mathrm{pC} \mathrm{m}^{-3} \mathrm{~s}^{-1}\right)$} \\
\hline & Maximum & Minimum & Maximum & Minmum \\
\hline $\mathrm{RH}=60 \%$ & 90.3 & -1.1 & 7.0 & 6.6 \\
\hline $\mathrm{RH}=70 \%$ & 148.4 & -0.3 & 17.2 & 16.4 \\
\hline $\mathrm{RH}=80 \%$ & 288.6 & -1.2 & 126.2 & 23.1 \\
\hline $\mathrm{RH}=90 \%$ & 574.1 & -99.6 & 140.6 & 72.8 \\
\hline
\end{tabular}
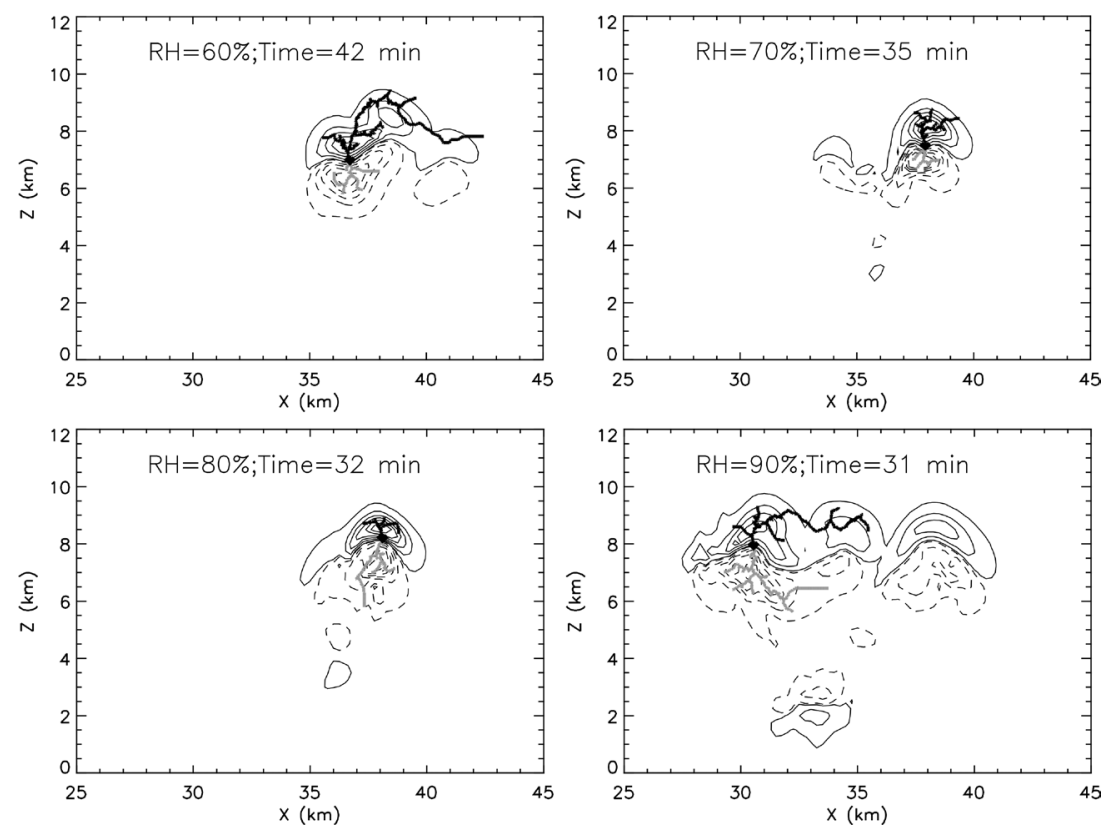

Fig. 8. Pre-discharge charge structure and lightning discharges in four cases. The solid is for positive charge and dashed is for negative charge, and black and gray lines are for negative and positive leader respectively, and black diamond is for lightning initiation point. The charge density contour is equal to $\pm 0.1, \pm 0.5, \pm 1, \pm 1.5, \pm 2, \pm 3 \mathrm{nC} \mathrm{m}^{-3}$.

charge is firstly produced between a pair of charge. When the RH increases from 60 - 90\%, the charge structure exhibits a tripole structure including a little lower positive charge region. Similarly, the first IC flash always occurs between a main positive charge region and a negative charge region in these cases. Additionally, there is a marked decrease in the time for the first lightning production from 42 - 31 min with the RH ranging from $70-90 \%$. The hydrometer particle concentration largely determines the electrification (e.g., Saunders and Peck 1998; Mansell et al. 2005; Guo et al. 2016). Aside from hydrometer particles concentration, two factors in hydrometer particles field that affect electrification the size and the fall speed of particle. The fall speed of ice crystal is relative small, while the fall speed of graupel depending on graupel diameter plays an important role in electrification. The finding of this study reveals that increasing RH causes a quicker and stronger hydrometer particles formation, leaving a quicker electrification and lightning generation.

Total lightning activities from four cases responding to the charge structure are shown in Fig. 9. The Qch is for the magnitude of charge. It can be found from Fig. 9 that the magnitude of charge (positive or negative) increases from $60-90 \%$. The main case is the stronger vigorous convection when the surface RH is high. A total of 3 IC lightning flashes are produced during the $60 \% \mathrm{RH}$ simulation (Fig. 9a). The initiation points for all lightning flashes reside in the high range of $6-10 \mathrm{~km}$, between an upper positive charge region and a lower negative charge region. The IC flashes are prone to be generated. A positive charge region arises, and thus charge structure is commonly referred to as the "normal tripole' during 35 - 39 min (see Fig. 9b). Since the electric field related to charge is weak in this region, lightning can not be produced during this period. After $39 \mathrm{~min}$, the storm turns to the dipole charge structure. A total of 7 IC lightning flashes are produced during $70 \% \mathrm{RH}$ simulation. Case 2 shows the stronger charge than Case 1 with $60 \%$ RH simulation, contributing to the initiation of more IC flashes. The results from $70 \% \mathrm{RH}$ and $80 \% \mathrm{RH}$ are comparable to each 
(a)

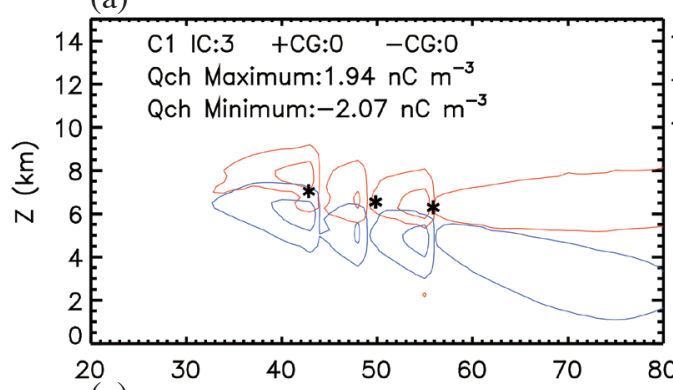

(c)

(b)

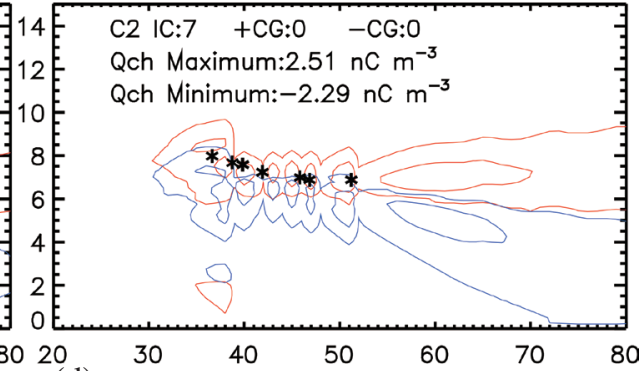

(d)
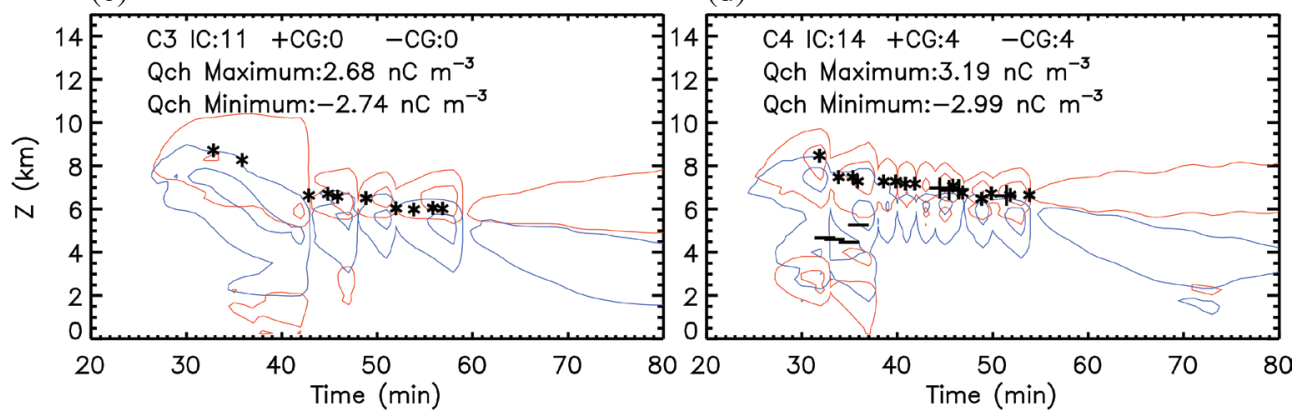

Fig. 9. Time-height maximum simulated charge separation in four cases (a) $\mathrm{RH}=60 \%$; (b) $\mathrm{RH}=70 \%$; (c) $\mathrm{RH}=80 \%$; (d) $\mathrm{RH}=90 \%$ (contours at $\pm 0.1, \pm 1, \pm 3, \pm 5, \pm 10, \pm 20 \mathrm{nC} \mathrm{m}^{-3}$, red lines denote positive charge, and blue lines indicate negative charge). Lightning initiation heights are indicated by $*(\mathrm{IC}),+(+\mathrm{CG}),-(-\mathrm{CG})$.

other, both composing a little low positive charge. Similarly, only IC flashes are produced in the case of $80 \%$ simulation (see Fig. 9c). Since the $80 \%$ RH case causes a greater charging rate, the number of IC flashes obtained from $80 \% \mathrm{RH}$ is larger than that in $70 \%$. The $90 \% \mathrm{RH}$ simulation produces a total of 22 lightning flashes, with 14 IC, 4 + CG and 4 -CG lightning flashes produced. A lower positive charge region is enhanced by inductive charging and noninductive charging processes, and this lower positive charge in thundercloud is suggested to a trigger for the negative CG lightning (Qie et al. 2005; Nag and Rakov 2009; Tan et al. 2014b). Therefore, the simulations employing the $90 \%$ produce 4 negative CG lightning flashes. In addition, the greater increase in the magnitude of charge at middle and upper levels, combined with the possibility of positive CG lightning occurring (see Fig. 9d). This is primary attributed to the increase of hydrometer content causing a greater electrification process. One can conclude that only $90 \%$ RH develops CG flashes that are not be involved in the other three cases.

\section{CONCLUSION}

In this work, we present an analysis of ten years measurements of lightning and relative humidity in Nanjing region, China. The data from $2002-2011$ are analyzed to investigate the relationship between lightning and humidity. The statistical analysis shows that the mean flash density roughly starts increasing from $75-95 \%$, and the stronger lightning activities over Nanjing city may be closely cor- related with the relative humidity that above $90 \%$. Application of statistical significance shows that lightning show positive correlation with relative humidity, with the correlation coefficient $\mathrm{R}$ is 0.43 .

To further elucidate the effect of relative humidity on electrification and lightning discharge. A two-dimensional cloud model is employed to simulate thunderstorms, and a sensitive study is present. Four cases are carried out driven by different the relative humidity at the surface. The increase of relative humidity condition generally leads to a quicker and stronger convection. The most noticeable effect of increasing RH is the enhancement of updraft velocity, which is closely connected with the stronger release of latent. Due to the activation of aerosol particle is primarily related with the absorption of water vapor, the great supersaturation in high RH cases leads to the enhancement of the cloud droplet formation. Additionally, the increase of the convection promotes the lift of drop particles, which leads to a faster production of ice particles. The enhanced graupel and ice crystal number concentration and mixing ratio with increasing RH is primarily due to enhanced cloud water content.

The storms electrification processes are dramatically affected by relative humidity. When RH increase from 60 $-90 \%$ at the surface, the noninductive charging rate and inductive charging rate increase significantly due to the enhancement of hydrometer particles formation. A faster and stronger charge separation is found to strongly dependent on higher RH condition. Therefore, the lightning production is very sensitive to RH at the surface. The thunderstorms 
only produce IC lightning flashes when the relative humidity increases from $60-80 \%$. However, a contributing factor in $90 \% \mathrm{RH}$ case is that the magnitude of charge at middle and low altitudes is stronger than that in the other three cases, so that it promotes more negative CG lightning flashes generation. In addition, some positive CG lightning flashes formed from a dipole charge structure in thunderstorms are found in $90 \%$ RH case.

The present study indicates the relatively humidity in the surface seems to play a significant role in the thunderstorm microphysics development, electrification, and lightning discharges. Some sensitive tests have been performed under other distinct conditions of $\mathrm{CCN}$. The conclusions are roughly consistent with the present study. Therefore, the conclusions gave from this study are valid. Future works should consider modifying other parameters such as temperature, aerosol, and topography to give a comprehensive evaluation. Additionally, a more detailed comparison study between the observation and simulated storm microphysics, lightning flashes should be presented in the frothing coming study.

Acknowledgements This work was supported by the National Key Basic Research Program of China (973 Program) 2014CB441403 and National Natural Science Foundation of China (Grant No. 41475006; No. 41805002) and the Startup Foundation for Introducing Talent of NUIST (2016r042) and Natural Science Foundation of Jiangsu Province (No. BK20180808; No. BK20150903) and Natural Science Fundamental Research Project of Jiangsu Colleges and Universities (No. 18KJB170010; No. 15KJB170010).

\section{REFERENCES}

Ackerman, A. S., M. P. Kirkpatrick, D. E. Stevens, and O. B. Toon, 2004: The impact of humidity above stratiform clouds on indirect aerosol climate forcing. Nature, $\mathbf{4 3 2}$, 1014-1017, doi: 10.1038/nature03174. [Link]

Brooks, I. M., C. P. R. Saunders, R. P. Mitzeva, and S. L. Peck, 1997: The effect on thunderstorm charging of the rate of rime accretion by graupel. Atmos. Res., 43, 277295, doi: 10.1016/S0169-8095(96)00043-9. [Link]

Carrió, G. G. and W. R. Cotton, 2014: On the buffering of CCN impacts on wintertime orographic clouds: An idealized examination. Atmos. Res., 137, 136-144, doi: 10.1016/j.atmosres.2013.09.011. [Link]

Cifelli, R., W. A. Petersen, L. D. Carey, S. A. Rutledge, and M. A.F. da Silva Dias, 2002: Radar observations of the kinematic, microphysical, and precipitation characteristics of two MCSs in TRMM LBA. J. Geophys. Res., 107, doi: 10.1029/2000JD000264. [Link]

Coleman, L. M., T. C. Marshall, M. Stolzenburg, T. Hamlin, P. R. Krehbiel, W. Rison, and R. J. Thomas, 2003: Effects of charge and electrostatic potential on lightning propagation. J. Geophys. Res., 108, doi:
10.1029/2002JD002718. [Link]

Cooper, W. A., 1980: A method of detecting contact ice nuclei using filter samples. Preprints, Eighth International Conference on Cloud Physics, Clermont-Ferrand, France, 665-668.

Dowdy, A. J. and G. A. Mills, 2012: Atmospheric and fuel moisture characteristics associated with lightning-attributed fires. J. Appl. Meteorol. Climatol., 51, 20252037, doi: 10.1175/JAMC-D-11-0219.1. [Link]

Fan, J., R. Zhang, G. Li, W.-K. Tao, 2007: Effects of aerosols and relative humidity on cumulus clouds. J. Geophys. Res., 112, doi: 10.1029/2006JD008136. [Link]

Fan, J., L. R. Leung, D. Rosenfeld, and P. J. DeMott, 2017: Effects of cloud condensation nuclei and ice nucleating particles on precipitation processes and supercooled liquid in mixed-phase orographic clouds. Atmos. Chem. Phys., 17, 1017-1035, doi: 10.5194/acp-17-1017-2017. [Link]

Feingold, G., W. L. Eberhard, D. E. Veron, and M. Previdi, 2003: First measurements of the Twomey indirect effect using ground-based remote sensors. Geophys. Res. Lett., 30, doi: 10.1029/2002GL016633. [Link]

Gardiner, B., D. Lamb, R. L. Pitter, J. Hallett, and C. P. R. Saunders, 1985: Measurements of initial potential gradient and particle charges in a Montana summer thunderstorm. J. Geophys. Res., 90, 6079-6086, doi: 10.1029/JD090iD04p06079. [Link]

Guo, F., G. Lu, X. Wu, H. Wang, Z. Liu, M. Bao, and Y. Li, 2016: Occurrence conditions of positive cloud-toground flashes in severe thunderstorms. Sci. China Earth Sci., 59, 1401-1413, doi: 10.1007/s11430-0165279-7. [Link]

Hu, Z. J. and G. F. He, 1987: Numerical simulations of cumulonimbus dynamic process, 1: Microphysical model. Acta, Meterol. Sinica, 45, 467-483. (in Chinese)

Jayaratne, E. R., C. P. R. Saunders, and J. Hallett, 1983: Laboratory studies of the charging of soft-hail during ice crystal interactions. Q. J. R. Meteorol. Soc., 109, 609-630, doi: 10.1256/smsqj.46110. [Link]

Kar, S. K., Y. A. Liou, and K. J. Ha, 2009: Aerosol effects on the enhancement of cloud-to-ground lightning over major urban areas of South Korea. Atmos. Res., 92, 8087, doi: 10.1016/j.atmosres.2008.09.004. [Link]

Khain, A., D. Rosenfeld, and A. Pokrovsky, 2005: Aerosol impact on the dynamics and microphysics of deep convective clouds. Q. J. R. Meteorol. Soc., 131, 26392663, doi: 10.1256/qj.04.62. [Link]

Khain, A.P., N. BenMoshe, and A. Pokrovsky, 2008: Factors determining the impact of aerosols on surface precipitation from clouds: An attempt at classification. J. Atmos. Sci., 65, 1721-1748, doi: 10.1175/2007JAS2515.1. [Link]

Köhler, H., 1936: The nucleus in and the growth of hygroscopic droplets. Trans. Faraday Soc., 32, 1152-1161, 
doi: $10.1039 /$ tf9363201152. [Link]

Lawrence, A., S. J. Warren, O. Almaini, A. C. Edge, N. C. Hambly, R. F. Jameson, P. Lucas, M. Casali, A. Adamson, S. Dye, J. P. Emerson, S. Foucaud, P. Hewett, P. Hirst, S. T. Hodgkin, M. J. Irwin, N. Lodieu, R. G. McMahon, C. Simpson, I. Smail, D. Mortlock, and M. Folger, 2007: The UKIRT infrared deep sky survey (UKIDSS). Mon. Not. Roy. Astron. Soc., 379, 15991617, doi: 10.1111/j.1365-2966.2007.12040.x. [Link]

Li, G. H., Y. Wang, and R. Zhang, 2008: Implementation of a two-moment bulk microphysics scheme to the WRF model to investigate aerosol-cloud interaction. J. Geophys. Res., 113, D15211, doi: 10.1029/2007JD009361. [Link]

Mansell, E. R. and C. L. Ziegler, 2013: Aerosol effects on simulated storm electrification and precipitation in a two-moment bulk microphysics model. J. Atmos. Sci., 70, 2032-2050, doi: 10.1175/JAS-D-12-0264.1. [Link]

Mansell, E. R., D. R. Macgorman, C. L. Ziegler, and J. M. Straka, 2005: Charge structure and lightning sensitivity in a simulated multicell thunderstorm. J. Geophys. Res., 110, D12101, doi: 10.1029/2004JD005287. [Link]

Mossop, S. C., 1976: Production of secondary ice particles during the growth of graupel by riming. Q.J.R. Meteorol.Soc., 102, 45-57, doi: 10.1256/smsqj.43103. [Link]

Naccarato, K. P., O. Pinto, and I. R. C. A. Pinto, 2003: Evidence of thermal and aerosol effects on the cloud-toground lightning density and polarity over large urban areas of Southeastern Brazil. Geophys. Res. Lett., 30, doi: 10.1029/2003GL017496. [Link]

Nag, A. and V. A. Rakov, 2009: Some inferences on the role of lower positive charge region in facilitating different types of lightning. Geophys. Res. Lett., 36, L05815, doi: 10.1029/2008GL036783. [Link]

Nakajima, T., A. Higurashi, K. Kawamoto, and J. E. Penner, 2001: A possible correlation between satellite-derived cloud and aerosol microphysical parameters. Geophys. Res.Lett.,28,1171-1174,doi: 10.1029/2000GL012186. [Link]

Petersen, W. A. and S. A. Rutledge, 2001: Regional variability in tropical convection: Observations from TRMM. J. Climate, 14, 3566-3586, doi: 10.1175/1520-0442(20 01)014<3566:RVITCO>2.0.CO;2. [Link]

Pruppacher, H. R. and J. D. Klett, 1997: Microphysics of Clouds and Precipitation, Kluwer Academic, Dordrecht, Netherlands, 954 pp.

Qie, X., T.Zhang, C. Chen, G. Zhang, T.Zhang, and W. Wei, 2005: The lower positive charge center and its effect on lightning discharges on the Tibetan Plateau. Geophys. Res. Lett., 32, L05814, doi: 10.1029/2004GL022162. [Link]

Rosenfeld, D., 1999: TRMM observed first direct evidence of smoke from forest fires inhibiting rainfall. Geophys. Res.Lett.,26,3105-3108, doi: 10.1029/1999GL006066.
[Link]

Rosenfeld, D., U. Lohmann, G. B. Raga, C. D. O’Dowd, M. Kulmala, S. Fuzzi, A. Reissell, and M. O. Andreae, 2008: Flood or drought: How do aerosols affect precipitation? Science, 321, 1309-1313, doi: 10.1126/science.1160606. [Link]

Saleeby, S. M., W. R. Cotton, D. Lowenthal, and J. Messina, 2013: Aerosol impacts on the microphysical growth processes of orographic snowfall. J. Appl. Meteorol. Climatol., 52, 834-852, doi: 10.1175/JAMCD-12-0193.1. [Link]

Saunders, C. P. R. and S. L. Peck, 1998: Laboratory studies of the influence of the rime accretion rate on charge transfer during crystal/graupel collisions. J. Geophys. Res., 103, 13949-13956, doi: 10.1029/97JD02644. [Link]

Saunders, C. P. R., W. D. Keith, and R. P. Mitzeva, 1991: The effect of liquid water on thunderstorm charging. $J$. Geophys. Res., 96, doi: 10.1029/91JD00970. [Link]

Shi, Z., Y. B. Tan, H. Q. Tang, J. Sun, Y. Yang, L. Peng, and X. F. Guo, 2015: Aerosol effect on the land-ocean contrast in thunderstorm electrification and lightning frequency. Atmos. Res., 164-165, 131-141, doi: 10.1016/j. atmosres.2015.05.006. [Link]

Shi, Z., H. Q. Tang, and Y. B. Tan, 2016: Effects of the inductive charging on the electrification and lightning discharges in thunderstorms. Terr. Atmos. Ocean. Sci., 27, 241-251, doi: 10.3319/TAO.2015.12.10.01(A). [Link]

Steiger, S. M., R. E. Orville, and G. Huffines, 2002: Cloud-to-ground lightning characteristics over Houston, Texas: 1989-2000. J. Geophys. Res., 107, doi: 10.1029/2001JD001142. [Link]

Sun, A., H. Chun, J. Baik, and M. Yan, 2002: Influence of electrification on microphysical and dynamical processes in a numerically simulated thunderstorm. $J$. Appl. Meteorol., 41, 1112-1127, doi: 10.1175/1520-04 50(2002)041<1112:IOEOMA>2.0.CO;2. [Link]

Takahashi, T., 1978: Riming electrification as a charge generation mechanism in thunderstorms. J. Atmos. Sci., 35, 1536-1548, doi: 10.1175/1520-0469(1978)035<15 36:REAACG $>2.0 . C O ; 2$. [Link]

Tan, Y., S. Tao, and B. Zhu, 2006: Fine-resolution simulation of the channel structures and propagation features of intracloud lightning. Geophys. Res. Lett., 33, L09809, doi: 10.1029/2005GL025523. [Link]

Tan, Y., Z. Liang, Z. Shi, J. Zhu, and X. Guo, 2014a: Numerical simulation of the effect of lower positive charge region in thunderstorms on different types of lightning. Sci. China Earth Sci., 57, 2125-2134, doi: 10.1007/s1 1430-014-4867-7. [Link]

Tan, Y.,S. Tao,Z.Liang, and B.Zhu, 2014b: Numerical study on relationship between lightning types and distribution of space charge and electric potential. J. Geophys. Res., 119, 1003-1014, doi: 10.1002/2013JD019983. [Link]

Tan, Y. B., L. Peng, Z. Shi, and H. R. Chen, 2016: 
Lightning flash density in relation to aerosol over Nanjing (China). Atmos. Res., 174-175, 1-8, doi: 10.1016/j. atmosres.2016.01.009. [Link]

Tan, Y. B., Z. Shi, Z. L. Chen, L. Peng, Y. Yang, X. F. Guo, and H. R. Chen, 2017: A numerical study of aerosol effects on electrification of thunderstorms. $J$. Atmos. Sol.-Terr. Phys., 154, 236-247, doi: 10.1016/j. jastp.2015.11.006. [Link]

Tao, S., Y. Tan, B. Zhu, M. Ma, and W. Lu, 2009: Fineresolution simulation of cloud-to-ground lightning and thundercloud charge transfer. Atmos. Res., 91, 360370, doi: 10.1016/j.atmosres.2008.05.012. [Link]

Wang, C., 2005: A modeling study of the response of tropical deep convection to the increase of cloud condensation nuclei concentration: 1 . Dynamics and microphysics. J. Geophys. Res., 110, D21211, doi: 10.1029/2004JD005720. [Link]

Williams, E. R. and G. Sátori, 2004: Lightning, thermodynamic and hydrological comparison of the two tropical continental chimneys. J. Atmos. Sol.-Terr. Phys., 66, 1213-1231, doi: 10.1016/j.jastp.2004.05.015. [Link]

Williams, E. R., R. Zhang, and J. Rydock, 1991: Mixedphase microphysics and cloud electrification. J. Atmos. Sci., 48, 2195-2203, doi: 10.1175/1520-0469(1991)04 8<2195:MPMACE $>2.0 . C O ; 2$. [Link]

Xiong, Y. J., X. S. Qie, Y. J. Zhou, T. Yuan, and T. L. Zhang, 2006: Regional responses of lightning activities to relative humidity of the surface. Chin. J. Geophys., 49, 311-318, doi: 10.1002/cjg2.840. [Link]

Yuan, T., L. A. Remer, K. E. Pickering, and H. Yu, 2011: Observational evidence of aerosol enhancement of lightning activity and convective invigoration. Geophys. Res. Lett., 38, L04701, doi: 10.1029/2010GL046052. [Link]

Zhao, P., Y. Yin, H. Xiao, Y. Zhou, and J. Liu, 2016: Role of water vapor content in the effects of aerosol on the electrification of thunderstorms: A numerical Study. Atmosphere, 7, 137, doi: 10.3390/atmos7100137. [Link]

Ziegler, C. L., D. R. Macgorman, J. E. Dye, and P. S. Ray, 1991: A model evaluation of noninductive graupelice charging in the early electrification of a mountain thunderstorm. J. Geophys. Res., 96, 12833-12855, doi: 10.1029/91JD01246. [Link]

\section{APPENDIX A. THE PARAMETERIZING APPROACHES OF CCN ACTIVATION}

$$
N_{c c n}=C_{o} S^{k}
$$

Where, $N_{c c n}$ is the number of activated CCN (Cloud Condensation Nuclei) and $S$ is the supersaturation of the cloud, $k$ is a constant and depends on the chemical composition and physical properties of the aerosol. Based on Wang (2005), $k$ is set to be 0.7 . For simplicity, $C_{o}$ is the concentration of
$\mathrm{CCN}$ activated numbers under $1 \%$ supersaturation and is used to indicate the initial aerosol concentration ( $\mathrm{Li}$ et al. 2008) in each numerical experiment. On this basis, this paper adds a diagnostic process to ensure that the model conforms to common sense.

$N_{c}=\max \left[\left(N_{c}^{\text {new }}-N_{c}^{\text {old }}\right) / \Delta t, 0\right]$

Where, $N_{c}^{\text {new }}$ is the calculated activation cloud droplet number concentration within a new time step $(\Delta t), N_{c}^{\text {old }}$ is the cloud droplet number concentration at the former time step, a new cloud droplet forms when $N_{c}^{\text {new }}>N_{c}^{\text {old }}$, and the activation rate is $N_{c}$.

\section{APPENDIX B. THE PARAMETERIZING APPROACHES OF NUCLEATION}

Nucleation of ice crystals are composed of homogeneous nucleation and heterogeneous nucleation. The homogeneous nucleation is described following the formula presented by Sun et al. (2002).

$Q_{c i f}= \begin{cases}p c \cdot Q_{c} / 2 \Delta t & -20^{\circ} \mathrm{C}<T<-40^{\circ} \mathrm{C} \\ Q_{c} / 2 \Delta t & T \leq-40^{\circ} \mathrm{C}\end{cases}$

where, $Q_{c i f}$ is the rate of cloud drop nucleation, $Q_{c}$ is the mixture ratio of cloud droplets, $(p c)$ is the percentage of water droplet freezing, $p c=0.008 \times(1.274)^{T_{0}-T}, T$ is the temperature within the cloud, $T_{0}$ is the temperature of the freezing of water droplets.

The heterogeneous nucleation is described following the formula presented by Cooper (1980) relating the number concentration of ice nuclei $\left(N_{i n}\right)$, ambient temperature $(T)$ :

$N_{\text {in }}=0.005 \times \exp (-0.304 \times T)-40^{\circ} \mathrm{C} \leq T \leq 0^{\circ} \mathrm{C}$

Where, $N_{\text {in }}$ is heterogeneous nucleation rate. Following $\mathrm{Hu}$ and $\mathrm{He}$ (1987), we taking into account the influence of water vapor supersaturation in the cloud, and thus the upper formula can be expressed as:

$$
N_{i n}=\left\{\begin{array}{l}
\frac{-0.304 \times 0.005 \times \exp (-0.304 \times T)}{\rho_{0}} \cdot\left(\frac{Q_{v}-Q_{s i}}{Q_{s w}-Q_{s i}}\right)^{k} \cdot \frac{d T}{d t} \\
\text { when } \frac{d T}{d t}<0 \text { and } Q_{v}>Q_{s i} \\
0 \text { when } \frac{d T}{d t} \geq 0 \text { and } Q_{v} \leq Q_{s i}
\end{array}\right.
$$

Where, $k=5, \frac{d T}{d t} \approx w \frac{\partial T}{\partial t}, w$ is wind speed. The heterogeneous nucleation rate is determined by temperature and water vapor supersaturation. 